Institute of $\mathbf{F}_{\text {ood and }} \mathbf{A}_{\text {gricultural }} \mathbf{S}_{\text {ciences }}$

\title{
Manual de los Reglamentos del Agua de Florida: Manejo de Desechos Sólidos ${ }^{1}$
}

\author{
Michael T. Olexa, Laura Minton, Dulcy Miller, y Sarah Corbett ${ }^{2}$
}

\section{Agradecimientos}

Los autores agradecen a Richard Budell de la Oficina de Política del Agua Agrícola del Departamento de Agricultura y Servicios al Consumidor de Florida. Los autores también agradecen a David H. Hammonds, Consultor del Programa de Salud Ambiental, Oficina de Programas de Aguas de Drenaje en el Sitio, del Departamento de Salud de Florida, y a Edward A. Bettinger, Consultor del Programa de Salud Ambiental, Oficina de Programas de Agua del Departamento de Salud de Florida.

\section{¿Quien Regula el Manejo de Desechos Sólidos?}

Ambos gobiernos, federal y estatal han aprobado el Acta de Recuperación y Conservación de los Recursos (ARCR), para ocuparse de la eliminación de los desechos sólidos. Las reglas federales, están administradas por la Agencia de Protección Ambiental (APA) y las reglas del estado, están administradas por el Departamento de Protección Ambiental (DPA).

Ambas ARCRs están dirigidas a proteger la salud y el medio ambiente y a reciclar o habilitar desechos sólidos al mayor grado practicable. Debido a que los desechos sólidos manejados inapropiadamente representan una amenaza para la

1. Este es el documento EDIS FE084, una publicación del Department of Food and Resource Economics, Florida Cooperative Extension Service, Institute of Food and Agricultural Sciences, University of Florida, Gainesville, FL. Publicada Noviembre 2002. Por favor visite la página electrónica EDIS en http://edis.ifas.ufl.edu.

2. Michael T. Olexa, es profesor del Department of Food and Resource Economics, Florida Cooperative Extension Service, Institute of Food and Agricultural Sciences, University of Florida, Gainesville, FL; y miembro de Florida Bar; Presidente de Agricultural Law Committee of The Florida Bar; y Director del Agricultural Law Center. Laura Minton, Dulcy Miller, y Sarah Corbett son estudiantes graduadas de Levin College of Law, University of Florida, Gainesville, FL. Filiberto Reyes-Villanueva fue el traductor de la versión en ingles al español.

Esta publicación esta diseñada para proporcionar información precisa, actualizada y autorizada sobre esta material. Sin embargo, ya que las leyes, reglas administrativas y decisiones de la corte, sobre las cuales están basados, están sujetas a revisión constante; algunas partes de esta publicación podrían ser obsoletas en cualquier momento. Esta publicación es distribuida bajo el entendimiento que los autores no están involucrados en ninguna representación legal u otros servicios profesionales, y que la información contenida aquí no debe ser considerada como un substituto de una asesoria legal. Esta publicación no esta completa en proporcionar toda la información para lograr el cumplimiento de las leyes y reglamentos que gobiernan la protección del agua. Por estas razones, el uso de estos manuales por cualquier persona constituye un acuerdo para mantener libre de daño a los autores, al Florida Cooperative Extension Service, al Institute of Food and Agricultural Sciences, y a la University of Florida por cualquier demanda por responsabilidad de daños, o gastos en que pueda incurrir cualquier persona, como un resultado de hacer referencia o confianza sobre la información contenida en esta publicación. Esta publicación fue apoyada financieramente por el Florida Department of Agriculture and Consumer Services.

EI Instituto de Alimentos y Ciencias Agrícolas es Un empleador que opera bajo Acción Afirmativa y provee Oportunidades Igualitarias, dedicado a promocionar la investigación, a información educativa y otros servicios, únicamente a los individuos e instituciones que operan baj discriminación sin considerar color, raza, sexo, edad, incapacidad u origen. Para más información sobre como obtener otras publicaciones de la extensión, comuníquese con la oficina de Servicio de Extensión de su condado. Servicio de Extensión de la Florida / Instituto de Alimentos y Ciencias Agrícolas / Universidad de la Florida / Christine Taylor Waddill, Decana. 
calidad del agua, esto también pertenece al ámbito de otras regulaciones federales, principalmente al Sistema Nacional para la Eliminación de Descargas Contaminantes (SNEDC) del Acta Federal de Agua Limpia. El SNEDC es un sistema con poder de la APA para exigir permisos de todas las fuentes que son descargas de contaminación de punto en las aguas navegables.

Aparte de las áreas de interés especial federal y estatal, las autoridades locales son básicamente libres de poner sus propias reglas, dentro de las guías mas amplias del estado, para la colecta y eliminación de desechos sólidos. Las ciudades, condados o municipalidades deben ser consultadas respecto a los problemas que involucran las ubicaciones de instalaciones para eliminación, frecuencia de colecta de desechos y otras preguntas, acerca de la eliminación diaria de los desechos.

\section{¿Qué es un Desecho Sólido?}

Un desecho sólido ha sido definido como cualquier basura, desperdicio, sedimento u otro material desechado; así como líquidos, semisólidos y materiales gaseosos confinados. Además, los desechos de las actividades agrícolas están expresamente incluidas. Los únicos materiales relevantes que están enlistados explícitamente como NO dentro de la ARCR son:

- drenaje domestico.

- desechos de flujo de retorno de riegos.

- descargas de fuente de punto que son permitidas para liberarse bajo el SNEDC del Acta de Agua Limpia.

Si ninguna de estas excepciones se aplica, y si el material involucrado puede decirse que es desechado o que ya sirvió para su propósito útil, es un desecho sólido. Los desechos sólidos también pueden ser reciclados, rehusados, eliminados, restaurados o almacenados, dependiendo de su naturaleza. Muchos desechos sólidos pueden también ser desechos peligrosos, y están sujetos a otros reglamentos mas estrictos. Por lo tanto, la sección sobre desechos peligrosos también debe ser consultada cuando se consideren desechos sólidos.
La cobertura del SNEDC se extiende solamente a las descargas en aguas navegables y pone diferentes estándares para la cantidad de desecho que se puede descargar en base a:

- el tipo de industria involucrada.

- la toxicidad del desecho.

- las cantidades máximas aceptables de elementos dañinos que se pueden liberar en el cuerpo de agua, el cual esta siendo contaminado.

La amplia definición del acta de "aguas navegables" es cubierta en el Acta de Agua Limpia, en la subsección del "Reglamento Federal" de este manual.

Las instalaciones que estén eliminando desechos de cualquier manera, y que no estén de acuerdo con las guías federales de la ARCR o los requerimientos de SNEDC para descargar agua, son juzgados por ser violadores de la ley.

\section{¿Qué son los Residuos?}

El DPA ha establecido reglamentaciones para controlar la aplicación de residuales a la tierra. Los residuos son sólidos, líquidos o semisólidos, generados durante el tratamiento de aguas de desecho domestico. Los residuos deberán ser aplicados a la tierra solamente si la instalación que genera o trata los residuos tiene un permiso válido en el cual incluye un Plan de Uso Agrícola aprobado para la aplicación en el sitio. Los residuos están clasificados como Clase A o Clase B de acuerdo a los requerimientos de reducción de patógenos llevado a cabo por la Agencia de Protección Ambiental (APA),estos son:

- Los residuos Clase A están permitidos sobre áreas publicas no restringidas como campos de deporte, parques, canchas de golf, césped y terreno de hospitales.

- Los residuos Clase B no están permitidos en áreas de acceso publico no restringidas. El uso de residuos Clase B esta limitado a áreas de acceso público como sitios agrícolas, bosques, andenes y bulevares de carreteras, y el público deberá ser restringido de las zonas de 
aplicación durante 12 meses después de la última aplicación residual. Adicionales restricciones son aplicados a suelos en donde se cosecha, crece y recolecta alimento y en sitios donde pastorean los animales.

Las precauciones que se aplican al uso o eliminación de residuos incluye lo siguiente:

- Los residuos nunca pueden ser tirados en los océanos o en aguas superficiales y subterráneas.

- Los residuos no deben ser descargados en sistemas de colección o transmisión sin previo consentimiento del dueño del sistema.

- Los residuos que contienen desechos peligrosos, nunca pueden ser aplicados a tierras agrícolas, y pueden requerir eliminación bajo regulaciones mas estrictas de desechos peligrosos.

\section{¿Cómo es Regulado el Aceite Usado?}

Tanto las leyes federales como estatales son consistentes en sus prohibiciones contra la eliminación peligrosa de aceite usado. Es claramente una violación al hacer:

- descargar aceites en suelos, desagües, sistemas de drenaje, tanques sépticos, aguas superficiales o subterráneas, cursos de agua o agua marina.

- tirar aceite en un lugar para enterrar desechos, o mezclar el aceite con otros desechos con el propósito de eliminarlo en una tierra para relleno con desechos.

- mezclar o combinar aceite usado con sustancias peligrosas que hagan al aceite usado no disponible para reciclado o uso benéfico.

- tirar aceite usado en un medio ambiente a través de cualquier proceso incluyendo control de malezas, control de polvo, aceitado de caminos u otros usos similares.

Además, todos los procesadores o transportadores de aceite usado deben registrarse en el DPA cada año, y todas las instalaciones para el manejo de aceite usado deben obtener permisos del DPA.

\section{¿De qué Desechos se Puede hacer Compost?}

El DPA ha establecido reglamentos detallados par la producción y uso del compost formado a partir de desechos. El enfoque de estos reglamentos no abarca el uso del compost obtenido de operaciones normales de granja sobre la tierra en que fue generado.

Usted puede hacer un compost como sigue:

- desechos producidos en "Operaciones normales de granja", tales como actividades usadas en la producción avícola, ganadera o cultivos agrícolas. Los desechos normales de estas operaciones incluyen desechos orgánicos, estiércol, y desechos derivados solamente de los cultivos agrícolas.

- cualquier instalación que produzca compost para vender debe obtener un permiso del DPA y cumplir con las regulaciones detalladas del DPA.

Usted No Puede Hacer compost como sigue:

- el compost de desechos sólidos nunca puede ser usado como material para relleno en cualquier cuerpo de agua superficial.

- los reglamentos del DPA prohíben cualquier aplicación de compost que amenace la salud publica o al medio ambiente.

\section{¿Qué No Debe Ir a las Tierras de Relleno?}

Florida ha tomado un interés en limitar los tipos de desechos sólidos para ser eliminados mediante entierro en tierras de relleno, y ha prohibido específicamente el uso de tierras de relleno para tirar los siguiente:

- aceite usado. 
- baterías de ácido-plomo.

- basura de patios.

- utensilios domésticos blancos (significando utensilios tirados como refrigeradores o calentadores de agua).

La quema de un desecho sólido esta también prohibido, excepto bajo las condiciones expresamente aprobadas por las reglas para las instalaciones de eliminación.

\title{
Fuentes
}

Código 42 de los Estados Unidos secciones 6901 a 6987; 40 Código de las Regulaciones Federales sección 240 et seq.; Código33 de los Estados Unidos secciones 1251 a 1387; Estatutos de Florida secciones 403. 702-. 7893; Titulo 17, Código Administrativo de Florida.

\section{Contacto de Información}

\author{
S-2, L-4, L-5, F-3, F-5
}

